\title{
Crónica de Derecho Canónico 2017
}

Joaquín SEDANO

Profesor Agregado de Historia del Derecho Canónico

Universidad de Navarra. Facultad de Derecho Canónico. Pamplona

orcid 0000-0002-7116-987X

jsedano@unav.es

Resumen: Se da noticia de los principales documentos y actos jurídicos dados en el año 2017 por el romano pontífice y los distintos dicasterios de la curia romana, así como de los acuerdos internacionales suscritos por la Santa Sede. También se hace referencia a la actividad canónica en el ámbito de la Conferencia Episcopal Española.

Palabras clave: Crónica, Derecho canónico, Actos pontificios, Curia romana, Acuerdos internacionales de la Santa Sede, Conferencia Episcopal Española.
Abstract: The Chronicle reports the main documents and legal acts issued in 2017 by the Pope and the various Dicasteries of the Roman Curia, as well as the international agreements signed by the Holy See. Canonical activity undertaken by the Spanish Episcopal Conference is also addresseed.

Keywords: Chronicle, Canon Law, Pontifical Acts, Roman Curia, International Agreements of the Holy See, Spanish Episcopal Conference.

SUMARIO: 1. Romano pontífice. 1.1. Escritos y documentos. 1.2. Erección y reorganización de circunscripciones eclesiásticas. 2. Curia romana. 2.1. Secretaría de Estado (Creación de la Sección Tercera). 2.2. Congregaciones. 2.2.1. Congregación para el Clero (Cambio de competencias sobre los santuarios). 2.2.2. Congregación para la Doctrina de la Fe (Autorización para la celebración del matrimonio de los fieles de la Fraternidad San Pío X). 2.2.3. Congregación para el Culto Divino y la Disciplina de los Sacramentos (Carta circular sobre el pan y el vino para la Eucaristía; carta ap. Magnum principium). 2.2.4. Congregación para las Causas de los Santos (Motu Proprio Maiorem hac dilectionem). 2.3. Consejos pontificios. 2.3.1. Consejo 
Pontifico para la Atención Espiritual de los Emigrantes e Itinerantes (cambio de competencias). 2.3.2. Consejo Pontificio para el Diálogo Interreligioso (Constitución grupo de trabajo Santa Sede-Palestina). 2.3.3. Consejo Pontificio para los Textos Legislativos (Respuestas particulares). 2.4. Comisiones pontificias. 2.5. Tribunales. 2.6. Consejo de los nueve cardenales. 3. Relaciones internacionales de la Santa Sede (Relaciones con China; reunión Comisión bilateral permanente de trabajo Santa Sede-Estado de Israel; acuerdo marco con el Congo; relaciones diplomáticas plenas con Myanmar; grupo de trabajo Santa Sede-Palestina). 4. Conferencia Episcopal Española (Estatutos de Santa María in Monserrato; unificación provincial de las Religiosas de María Inmaculada; unificación provincial de los Misioneros Paúles; nuevo Misal castellano; actualización normas de la BAC; aprobación y modificación de estatutos).

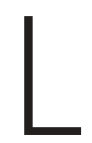

o más destacado del año 2017, desde la perspectiva canónica, han sido los diversos actos pontificios que, en forma Motu Proprio, han modificado el ordenamiento canónico en diferentes aspectos.

Así, la carta ap. Sanctuarium in Ecclesia, transfiere la competencia sobre los santuarios de la Congregación para el Clero al Consejo Pontificio para la Promoción de la Nueva Evangelización, quedando modificados los arts. 97, $1^{\circ}$ y 151 de la Const. Apost. Pastor bonus. La carta ap. Magnum principium, sobre la edición, traducción y adaptación a las lenguas vernáculas de los textos litúrgicos, modifica la redacción del c. 838 y afecta a la interpretación del art. 64, $\$ 3$ de la Pastor bonus.

Por otra parte, con motivo de la audiencia a los participantes en un curso organizado por la Rota Romana, el papa Francisco quiso realizar una serie de aclaraciones sobre los Motu Proprio Mitis iudex y Mitis et misericors en relación con la figura del obispo diocesano en el proceso brevior y las competencias otorgadas al decano de la Rota Romana por la nueva redacción del c. 1687 .

Además, cabe también destacar la refundación del Instituto Juan Pablo II sobre matrimonio y familia y la carta del prefecto de la Congregación para el Culto Divino y la Disciplina de los Sacramentos con diversas indicaciones para asegurar que en el contexto actual de globalización se confeccionen adecuadamente el pan y el vino usados para la Eucaristía. 


\section{ROMANO PONTÍFICE}

\subsection{Escritos y documentos (Discurso a la Rota Romana; carta ap.} Sanctuarium in Ecclesia; carta ap. Maiorem bac dilectionem; carta ap. Magnum principium; carta ap. Summa familiae cura; interpretación auténtica de los Motu Proprio Mitis iudex y Mitis et misericors)

- El 21 de enero, en el discurso con motivo de la inauguración del año judicial, el papa Francisco quiso tratar de la relación entre la fe y el matrimonio. Partiendo de dos textos de Juan Pablo II (Enc. Fides et ratio n. 16) y de Benedicto XVI (Discurso a la Rota Romana, 26-I-2013) puso en evidencia cómo el actual contexto generalizado carente de valores religiosos y de fe, también entre los cristianos, «no puede por menos que condicionar también el consentimiento matrimonial».

Para paliar esta situación, el papa propone dos remedios relacionados con la formación. El primero debe ir dirigido a los futuros cónyuges, de modo que la preparación para el matrimonio suponga una ocasión de "verdadera y propia evangelización”. Se trata de conseguir que los itinerarios de preparación sean más eficaces y que ayuden a los novios no sólo a que reciban el matrimonio válida y lícitamente, sino también fructuosamente. En este sentido, aludiendo a los deseos de los padres sinodales del último sínodo ordinario de los obispos y a las disposiciones de Familiaris consortio n. 66, el papa habla de la necesidad de configurar un "nuevo catecumenado" para la preparación al matrimonio, de modo que sirva «como un antídoto para evitar la proliferación de celebraciones matrimoniales nulas o inconsistentes».

El segundo remedio se refiere al acompañamiento, mediante un adecuado proyecto de formación de los recién casados.

En ambos casos alude a la necesidad de una nueva toma de conciencia por parte de los párrocos y al apoyo de parejas de matrimonios verdaderamente preparados y competentes para prestar este servicio de formación y acompañamiento pastoral.

- Con fecha de 11 de febrero el romano pontífice emitió la carta apostólica en forma de Motu Proprio Sanctuarium in Ecclesia, con el propósito de dar un nuevo impulso a los santuarios.

El más relevante de los aspectos jurídicos de este documento es la transferencia de las competencias sobre los santuarios de la Congregación para el Clero (art. 97, $1^{\circ}$ Const. Apost. Pastor bonus) al Consejo Pontificio para la Pro- 
moción de la Nueva Evangelización. Este dicasterio asume también la competencia atribuida por el art. 151 de la Pastor bonus al Consejo Pontificio para la Atención Espiritual de los Emigrantes e Itinerantes en relación con los viajes por motivos de piedad.

La carta apostólica concede al Consejo Pontificio para la Promoción de la Nueva Evangelización las siguientes atribuciones: «a) la erección de Santuarios internacionales y la aprobación de sus respectivos estatutos, de acuerdo con los cc. 1232-1233 del CIC. b) el estudio y la aplicación de medidas para promover la función evangelizadora de los Santuarios y el cultivo en ellos de la piedad popular. c) la promoción de una pastoral orgánica de los Santuarios como centros propulsores de la nueva evangelización. d) la promoción de encuentros nacionales e internacionales para promover una obra de renovación pastoral común de la pastoral de la piedad popular y de las peregrinaciones a los lugares de culto. e) la promoción de la formación específica de los operadores de los Santuarios y de los lugares de piedad y devoción. f) la vigilancia para que se ofrezca a los peregrinos, en los lugares del recorrido, una asistencia espiritual y eclesial coherente y sostenida que favorezca los mejores frutos personales de estas experiencias. g) la valorización cultural y artística de los Santuarios según la via pulcbritudinis como un modo particular de evangelización de la Iglesia».

Esta carta apostólica fue promulgada mediante su publicación el día 1 de abril en el diario L'Osservatore Romano y, según las indicaciones del mismo documento, entró en vigor el 16 de ese mismo mes.

- El 11 de julio el papa firmó la carta apostólica Maiorem hac dilectionem, por la que constituye una nueva vía para la apertura de las causas de beatificación y canonización. La nueva causa consiste en el ofrecimiento de la vida, que se une a las otras ya existentes: el martirio y el ejercicio heroico de las virtudes cristianas.

La carta, en su art. 2, establece una serie de requisitos que se deben cumplir para que el ofrecimiento de la vida pueda dar cauce a la introducción del proceso de beatificación: «a) ofrecimiento libre y voluntario de la vida y heroica aceptación propter caritatem de una muerte segura, y a corto plazo; b) relación entre el ofrecimiento de la vida y la muerte prematura; c) el ejercicio, por lo menos en grado ordinario, de las virtudes cristianas antes del ofrecimiento de la vida y, después, hasta la muerte; d) existencia de la fama de santidad y de los signos, al menos después de la muerte; e) necesidad del milagro 
para la beatificación, sucedido después de la muerte del Siervo de Dios y por su intercesión».

La introducción de esta nueva causa, modifica ligeramente las disposiciones de la const. ap. Divinus perfectionis Magister de 25-I-1983 (arts. 1, 2.5, $7.1,13.2)$ y de las «Normae servandae in inquisitionibus ab Episcopis facendis in Causis Sanctorum» de 7-II-1983 (arts. 7, 10. $1^{\circ}$ y 3o 15.a-b, 19, 32, 36).

La carta apostólica fue promulgada mediante su publicación en el diario L'Osservatore Romano en su edición de 11 de julio y entró en vigor ese mismo día.

- El 1 de octubre entró en vigor la carta apostólica en forma de Motu Proprio Magnum principium, fechada el 3 de septiembre. Este documento papal modifica el c. 838, relativo a la edición, traducción y adaptación a las lenguas vernáculas de los textos litúrgicos. El Motu Proprio. pretende definir mejor las competencias de la Sede Apostólica -ejercidas de modo habitual a través de la Congregación para el Culto Divino y la Disciplina de los Sacramentosy de las conferencias episcopales sobre esta materia.

Tras la experiencia acumulada desde la celebración del Concilio Vaticano II, se ha visto oportuno revisar las diversas normas dadas en esta materia, especialmente los arts. 36, $\$ \$ 3-4,40$ y 63 de la const. Sacrosanctum Concilium, el n. 21 de la instr. Inter Oecumenici (26-IX-1964) y el n. IX de la carta ap. $S a$ cram Liturgiam (28-III-2001), y queden expresadas con mayor claridad en la redacción del c. 838, de modo que «aparezca mejor la competencia de la Sede Apostólica respecto a la traducción de los libros litúrgicos y las adaptaciones más profundas, entre las que se pueden incluir también posibles nuevos textos que se incorporarán a ellos, establecidos y aprobados por las Conferencias Episcopales».

En atención a estas indicaciones, el sumo pontífice decretó la modificación del c. 838 en los siguientes términos. Allí donde el parágrafo segundo afirmaba que compete a la Sede Apostólica revisar las «traducciones a lenguas vernáculas» de los libros litúrgicos, ahora se establece que compete a la Sede Apostólica revisar las «adaptaciones aprobadas según la norma del derecho por la conferencia episcopal». Donde el parágrafo tercero indicaba que «corresponde a las Conferencias Episcopales preparar las traducciones de los libros litúrgicos a las lenguas vernáculas», se añade el adverbio «fielmente». En este mismo parágrafo, donde decía que debían adaptar las traducciones «y editarlas con la revisión previa de la Santa Sede», se establece ahora que deben además «aprobarlas (...) para las regiones de su pertinencia (...) después de la 
confirmación de la Sede Apostólica». El $₫ 3$ queda, así, de la siguiente manera: «Corresponde a las Conferencias Episcopales preparar fielmente las versiones de los libros litúrgicos en las lenguas vernáculas, adaptadas convenientemente dentro de los límites definidos, aprobarlas y publicar los libros litúrgicos, para las regiones de su pertinencia, después de la confirmación de la Sede Apostólica».

La modificación de este canon afecta a diversas normas, como advierte el mismo Motu Proprio: «De manera consecuente se han de interpretar sea el artículo 64, $\$ 3$ de la Constitución Apostólica Pastor bonus sean las otras leyes, en particular las contenidas en los libros litúrgicos, acerca de sus versiones. De la misma manera dispongo que la Congregación para el Culto Divino y la Disciplina de los Sacramentos modifique su "Reglamento" basándose en la nueva disciplina y ayude a las Conferencias Episcopales a llevar a cabo su tarea y trabaje para promover cada vez más la vida litúrgica de la Iglesia Latina».

Los aspectos más complejos se refieren a la adecuada distinción entre la recognitio y la confirmatio. El secretario de la Congragación para el Culto Divino y la Disciplina de los Sacramentos, mons. Roche, publicó un comentario en la web del dicasterio donde precisaba que la recognitio «implica el proceso de reconocimiento de las legítimas adaptaciones litúrgicas por parte de la Sede apostólica, comprendidas aquellas "más profundas", que las conferencias episcopales pueden establecer y aprobar para sus territorios, en los límites permitidos. En este ámbito de encuentro entre liturgia y cultura, la Sede Apostólica está llamada a recognoscere, es decir, a revisar y valorar las adaptaciones, con el fin de salvaguardar la unidad sustancial del rito romano (...) La confirmatio (...) se refiere a la traducción de los textos litúrgicos que, según Sacrosanctum Concilium (n. 36, $\$ 4$ ), compete preparar y aprobar a las conferencias episcopales; el $\$ 3$ del canon 838 precisa que las traducciones tienen que ser llevadas a cabo fideliter, según los textos originales, recogiendo así la preocupación principal de la instrucción Liturgiam authenticam. De hecho, recordando el derecho y la tarea de la traducción confiada a las conferencias episcopales, el Motu Proprio recuerda, además, que las mismas conferencias "tienen que asegurar que, salvaguardado el genio de cada lengua, se vea plena y fielmente el sentido del texto original". La confirmatio de la Sede Apostólica no se entiende, por tanto, como una intervención alternativa en el proceso de traducción, sino como un acto de autoridad con el cual el dicasterio competente ratifica la aprobación de los obispos; suponiendo una valoración positiva de la fidelidad y de la congruencia de los textos elaborados con respecto a la edición típica, 
sobre la cual se funda la unidad del rito, y teniendo en cuenta, sobre todo, los textos de mayor importancia, particularmente las fórmulas sacramentales, las plegarias eucarísticas, las plegarias de ordenación, el rito de la misa, etc.».

El card. Sarah, prefecto de la Congregación para el Culto Divino y la Disciplina de los Sacramentos, publicó en la revista L'Homme Nouveau ${ }^{1}$ un comentario sobre la carta ap. Magnum principium. Entre otros aspectos, afirmaba el cardenal que los términos recognitio y confirmatio serían sinónimos e intercambiables y que la Congregación que él preside seguía teniendo la competencia para la aprobación de las traducciones litúrgicas realizadas por las respectivas conferencias episcopales.

El 22 de octubre, el Papa Francisco hizo pública una carta suya fechada el día 15 del mismo mes. En ella comunicaba que el 30 de septiembre el card. Sarah le había hecho llegar una carta con el comentario que había enviado para publicación a la revista L'Homme Nouveau. El santo padre corrigió la interpretación dada por el purpurado a Magnum principium y aportó una interpretación auténtica que desautorizaba la afirmación del card. Sarah de que los términos recognitio y confirmatio eran sinónimos e intercambiables. Por su interés reproduzco la traducción de la parte central de la carta ${ }^{2}$ : «Ante todo, es necesario señalar la importancia de la neta diferencia que el nuevo Motu Proprio establece entre recognitio y confirmatio, bien sancionada en los $\$ \$ 2$ y 3 del c. 838, para abolir la praxis adoptada por el Dicasterio de acuerdo a Liturgiam authenticam (en adelante LA) y que el nuevo Motu Proprio ha querido modificar. No se puede decir, por lo tanto, que recognitio y confirmatio son "estrictamente sinónimos (o) son intercambiables" o "son intercambiables en el nivel de responsabilidad de la Santa Sede"».

En realidad, el nuevo c. 838, a través de la distinción entre recognitio y confirmatio, afirma la diversa responsabilidad de la Sede Apostólica en el ejercicio de estas dos acciones, así como la de las Conferencias Episcopales. Magnum

\footnotetext{
${ }^{1} \mathrm{~N}^{\mathrm{o}}$ 1648, de 14 de octubre de 2017: https://www.hommenouveau.fr/2306/religion/humble-contribution-pour-une-meilleure-et-juste-brcomprehension-du-motu-proprio-magnum-principium.htm.

2 El original italiano lo he consultado en el siguiente link: https://infovaticana.com/wpcontent/uploads/2017/10/Carta-papa-Sarah.pdf. Resulta extraño que a finales de abril de 2018 -cuando se redactan estas líneas- no se encuentre todavía publicada ninguna versión oficial de esta carta, ni en el sitio web del Vaticano con los documentos del pontífice ni en la web de la Congregación (no he podido consultar las ediciones de L'Osservatore Romano de esos días). Ante las deficiencias encontradas en las versiones castellanas difundidas en la web, he realizado por mí mismo la traducción del documento.
} 
Principium no sostiene ya que las traducciones deban ser conformes en todos los puntos a las normas de LA, como se afirmaba en el pasado. Por esta razón, cada uno de los números de LA deben ser atentamente re-entendidos, incluidos los nn. 79-84, al fin de distinguir lo que exige el código para la traducción y lo que se requiere para las adaptaciones legítimas. Por lo tanto, queda claro que algunos números de LA han sido derogados o han caído en los términos en los que han sido reformulados por el nuevo canon del Motu Proprio (p. ej. el n. 76 y el n. 80).

Sobre la responsabilidad de las Conferencias Episcopales de traducir fideliter, es necesario precisar que el juicio acerca de la fidelidad al latín y las eventuales correcciones necesarias era competencia del Dicasterio, mientras que ahora la norma concede a las Conferencias Episcopales la facultad de juzgar la bondad y la coherencia de uno y otro término en las traducciones del original, si bien en diálogo con la Santa Sede. La confirmatio ya no supone, pues, un examen detallado palabra por palabra, excepto en los casos evidentes que pueden ser hechos presentes a los Obispos para su posterior reflexión. Esto vale en particular para las fórmulas relevantes, como para las Plegarias Eucarísticas y en particular las fórmulas sacramentales aprobadas por el Santo Padre. La confirmatio tiene también en cuenta la integridad del libro, es decir, verifica que todas las partes que componen la edición típica hayan sido traducidas.

Aquí se puede añadir que, a la luz del Motu Proprio, el fideliter del $\$ 3$ del canon, implica una triple fidelidad: al texto original in primis; a la lengua particular en que se traduce y, finalmente, a la comprensibilidad del texto por parte de los destinatarios (cfr. Institutio Generalis Missalis Romani, nn. 391-392).

En este sentido, la recognitio indica solamente la verificación y la salvaguarda de la conformidad al derecho y a la comunión de la Iglesia. El proceso de traducir los textos litúrgicos relevantes (p. ej. fórmulas sacramentales, el Credo, el Pater noster) en una lengua -de las que son consideradas traducciones auténticas-, no debería llevar a un espíritu de "imposición” a las Conferencias Episcopales de una determinada traducción realizada por el Dicasterio, ya que esto lesionaría el derecho de los Obispos consagrado en el canon y, ya antes, en SC 36, $\$ 4$. Por lo demás, téngase presente la analogía con el c. $825, \$ 1$ sobre la versión de la Sagrada Escritura, que no requiere de confirmatio por parte de la Sede Apostólica.

Resulta inexacto atribuir a la confirmatio la finalidad de la recognitio (es decir, «verificar y salvaguardar la conformidad con el derecho»). Ciertamente, la 
confirmatio no es un acto meramente formal, aunque necesario para la edición del libro litúrgico "traducido": «se concede después de que la versión haya sido sometida a la Santa Sede para la ratificación de la aprobación de los Obispos, en espíritu de diálogo y de ayuda para reflexionar cuando fuese necesario, respetando los derechos y deberes, considerando la legalidad del proceso seguido y sus modalidades».

Se despide el Santo Padre solicitando al card. Sarah que difunda esta carta en los mismos lugares donde se ha publicado la interpretación privada del cardenal, así como entre los miembros y consultores del dicasterio que preside y que se envíe a las conferencias episcopales.

- Con fecha de 8 de septiembre el papa publicó la carta apostólica en forma de motu proprio Summa familiae cura, por la que instituyó el Instituto Pontificio Teológico Juan Pablo II para las Ciencias del Matrimonio y de la Familia.

Esta nueva institución sustituye y sucede al Instituto Pontificio Juan Pablo II para estudios sobre el Matrimonio y la Familia, establecido por la const. ap. Magnum Matrimonii sacramentum (7-X-1982) en el seno de la Universidad Pontificia Lateranense. En la exposición de motivos el pontífice justifica esta medida en la atención central que la Iglesia ha pasado a dedicar al matrimonio y la familia a partir de los sínodos de los obispos de 2014 y 2015 y de la exhort. ap. postsinodal Amoris laetitia (19-III-2016), así como en los nuevos desafíos antropológicos, culturales y pastorales que afronta la institución familiar.

El deseo de una mejor inteligencia en el tiempo presente de la verdad revelada y de un nuevo enfoque analítico y audaz de la situación actual de la familia ha llevado al papa Francisco a modificar el marco jurídico del Instituto Juan Pablo II. Así, en sus seis artículos, dispone: la nueva estructura académica del Instituto (con las figuras del gran canciller, presidente y consejo); una especial relación con la Congregación para la Educación Católica, el Consejo Pontificio para los Laicos, la Familia y la Vida, y con la Academia Pontificia para la Vida; la facultad de conferir iure proprio los títulos académicos de diplomatura, licenciatura y doctorado en Ciencias sobre el matrimonio y la familia; y la redacción de unos nuevos estatutos que detallen los aspectos más concretos del funcionamiento del nuevo instituto, entre ellos, la cooperación con la Universidad Pontificia Lateranense.

- El 25 de noviembre, con motivo de un discurso a los participantes en el curso «El nuevo proceso matrimonial y el procedimiento super rato», orga- 
nizado por el Tribunal de la Rota Romana, el papa quiso «aclarar definitivamente algunos de los aspectos fundamentales» de los Motu Proprio Mitis iudex Dominus fesus y Mitis et misericors Iesus, en relación con la figura del obispo diocesano como juez personal y único en el proceso brevior.

Destaco a continuación los elementos principales de los nueve puntos indicados por el pontífice. En primer lugar, recuerda que el obispo «en razón de su oficio pastoral es juez personal y único» en el proceso más breve (n. 1). Para la validez del proceso brevior se requieren dos condiciones inseparables: que el juez sea obispo y cabeza de una comunidad diocesana (n. 3).

El proceso brevior, cuando se cumplan los requisitos previstos, «no es una opción que el obispo diocesano pueda elegir, sino una obligación». Se precisa que el obispo tiene la competencia exclusiva en las tres fases del proceso: la instancia, la instrucción y la sentencia. La instrucción debe ser llevada a cabo por el obispo, aunque asistido por el vicario judicial u otro instructor, el asesor y el defensor del vínculo. Si la diócesis careciera de canonistas podría ser socorrida por un obispo vecino. Por otra parte, la sentencia es decisión «siempre y sólo del obispo diocesano» (n. 5).

En aras de la celeridad, en el supuesto de que el obispo diocesano no se sintiera preparado en ese momento, remitirá la causa al proceso ordinario para que sea llevada con la debida diligencia (n. 7). Se vuelve a insistir también, de una manera indeterminada, en los criterios de proximidad y gratuidad (n. 8).

En último lugar, el papa afirma que las nuevas competencias dadas por la nueva redacción del c. 1687 al decano de la Rota Romana en el caso de apelación contra sentencia afirmativa, no requieren de permiso o autorización de la Signatura Apostólica o de cualquier otra institución (n. 9).

\subsection{Erección y reorganización de circunscripciones eclesiásticas}

- El 2 de enero, el papa Francisco erigió la diócesis de Danlí (población 450.000, 18 sacerdotes, 26 religiosos) en Honduras, con territorio desmembrado de la diócesis de Tegucigalpa y haciéndola sufragánea de la archidiócesis metropolitana de Tegucigalpa.

- El 8 de febrero erigió la diócesis de Maintirano (población 264.494, 31.205 católicos, 16 sacerdotes, 26 religiosos) en Madagascar, con territorio desmembrado de las diócesis de Tsiroanomandidy, Mahajanga y Morondava, haciéndola sufragánea de la sede metropolitana de Antananarivo. 
- El 30 de noviembre elevó el vicariato apostólico de Bluefields, en Nicaragua, al rango de diócesis haciéndola sufragánea de la archidiócesis de Managua.

El mismo día erigió la diócesis de Siuna, también en Nicaragua, y haciéndola sufragánea de Managua.

En relación con las Iglesias orientales católicas,

- El 5 de agosto el Sínodo de los Obispos de la Iglesia arzobispal mayor siro-malankar, previa consulta a la Sede Apostólica, erigió la eparquía de Parassala (30.750 fieles) en la India, con territorio desmembrado de la archieparquía de Trivandrum.

- El 12 de septiembre el Sínodo de los Obispos de la Iglesia greco-católica ucraniana, previa consulta a la Sede Apostólica, erigió la eparquía de Chernivtsi, con sede en la misma ciudad y con territorio desmembrado de la eparquía de Kolomyia-Chernivtsi, haciéndola sufragánea de la sede metropolitana de Ivano-Frankivsk.

- El 10 de octubre erigió, en el seno de la Iglesia siro-malabar en la India, las eparquías de Shamshabad (en el Estado de Telangana) y Hosur (en el distrito de Krishnagiri del Estado de Tamil Nadu). Amplió también los límites de las eparquías de Ramanathapuram y Thuckalay, en el mismo país.

\section{CURIA ROMANA}

\subsection{Secretaría de Estado (Creación de la Sección Tercera)}

El 21 de noviembre la Secretaría de Estado hizo público que el santo padre había constituido la Sección Tercera de este organismo, con la denominación de Sección del Personal de rol diplomático de la Santa Sede, reforzando de este modo el apoyo al Delegado de las Representaciones Pontificias.

La principal finalidad de la nueva sección consiste en «demostrar la atención y la cercanía del Santo Padre y de los superiores de la Secretaría de Estado al personal de rol diplomático».

Queda como competencia exclusiva de la Tercera Sección los asuntos relacionados con las personas que trabajan o se preparan para trabajar en el ser- 
vicio diplomático de la Santa Sede (selección, formación inicial y permanente, condiciones de vida y de servicio, ascensos, permisos, etc).

En su desempeño debe guardar una estrecha colaboración con la Sección de Asuntos Generales -que se ocupa de las Representaciones Pontificias- y con la Sección de Relaciones con Estados -que trata los aspectos políticos del trabajo de las Representaciones Pontificias-.

\subsection{Congregaciones}

\subsubsection{Congregación para el Clero (Cambio de competencias sobre los santuarios)}

Sobre el cambio de competencias en relación con los santuarios (cfr. art. 97, $1^{\circ}$ Pastor bonus) en favor del Consejo Pontificio para la Promoción de la Nueva Evangelización vid. carta ap. Sanctuarium in Ecclesia en Escritos y documentos del romano pontífice (apdo. 1.1).

\subsubsection{Congregación para la Doctrina de la Fe (Autorización para la} celebración del matrimonio de los fieles de la Fraternidad San Pío X)

Sobre la autorización a los obispos diocesanos de conceder licencias para la celebración del matrimonio de los fieles de la Fraternidad San Pío X, vid. Comisión Pontificia Ecclesia Dei (apdo. 2.3).

\subsubsection{Congregación para el Culto Divino y la Disciplina de los Sacramentos} (Carta circular sobre el pan y el vino para la Eucaristía; carta ap. Magnum principium)

- El 15 de junio el card. Robert Sarah, prefecto de esta congregación, publicó una carta circular a los obispos sobre el pan y el vino que se debe usar en la Eucaristía.

El documento, redactado por encargo del papa Francisco, manifiesta la preocupación ante los nuevos escenarios donde se confecciona y se vende el pan y el vino para la Misa, como supermercados y venta online. El documento recuerda diversos textos y normas en relación con la materia eucarística (cfr. c. 924, n. 319 Institutio generalis Missalis Romani, instr. Redemptionis sacramentum). Por su interés y actualidad, reproduzco algunos de estos textos recogidos en la carta circular. 
«a) El pan que se emplea en el santo Sacrificio de la Eucaristía debe ser ázimo, de sólo trigo y hecho recientemente, para que no haya ningún peligro de que se corrompa. Por consiguiente, no puede constituir la materia válida, para la realización del Sacrificio y del Sacramento eucarístico, el pan elaborado con otras sustancias, aunque sean cereales, ni aquel que lleva mezcla de una sustancia diversa del trigo, en tal cantidad que, según la valoración común, no se puede llamar pan de trigo (...).

b) El vino que se utiliza en la celebración del santo Sacrificio eucarístico debe ser natural, del fruto de la vid, puro y sin corromper, sin mezcla de sustancias extrañas (...) Está totalmente prohibido utilizar un vino del que se tiene duda en cuanto a su carácter genuino o a su procedencia» (Instr. Redemptionis sacramentum nn. 48 y 50).

La carta recuerda también el texto de la carta circular a los presidentes de las conferencias episcopales acerca del uso del pan con poca cantidad de gluten y del mosto como materia eucarística (24-VII-2003). Nuevamente reproduzco alguno de estos textos recogidos en la carta de 2017.

«a) Las hostias sin nada de gluten son materia inválida para la Eucaristía. Son materia válida las hostias con la mínima cantidad de gluten necesaria para obtener la panificación sin añadir sustancias extrañas ni recurrir a procedimientos que desnaturalicen el pan (A. 1-2).

b) Es materia válida para la Eucaristía el mosto, esto es, el zumo de uva fresco o conservado, cuya fermentación haya sido suspendida por medio de procedimientos que no alteren su naturaleza (por ejemplo el congelamiento) (A. 3).

c) Es competencia del Ordinario conceder a los fieles y a los sacerdotes la licencia para usar pan con una mínima cantidad de gluten o mosto como materia para la Eucaristía. La licencia puede ser concedida habitualmente, mientras dure la situación que la ha motivado (C. 1)».

Se recuerda también que «la eucarística preparada con organismos genéticamente modificados puede ser considerada materia válida» (Carta al Prefecto de la Congregación para el Culto Divino y la Disciplina de los Sacramentos acerca de la materia eucarística preparada con organismos genéticamente modificados, 9-XII-2013).

El documento invita a los obispos a establecer las indicaciones oportunas para salvaguardar la adecuada confección del pan y el vino para la Eucaristía, sea individualmente, sea a través de las respectivas conferencias episcopales. 
- Sobre la reforma del c. 838 en relación con la edición, traducción y adaptación a las lenguas vernáculas de los textos litúrgicos, vid. Motu Proprio Magnum principium en Escritos y documentos del romano pontífice (apdo. 1.1).

\subsubsection{Congregación para las Causas de los Santos (Motu Proprio Maiorem hac dilectionem)}

Sobre la nueva vía para las causas de beatificación y canonización con motivo del ofrecimiento de la propia vida, vid. Motu Proprio Maiorem hac dilectionem en Escritos y documentos del romano pontífice (apdo. 1.1).

\subsection{Consejos pontificios}

\subsubsection{Consejo Pontifico para la Atención Espiritual de los Emigrantes e Itinerantes (cambio de competencias)}

Sobre el cambio de competencias en relación con los viajes por motivos de piedad (cfr. art. 151 Pastor bonus) en favor del Consejo Pontificio para la Promoción de la Nueva Evangelización vid. carta ap. Sanctuarium in Ecclesia en Escritos y documentos del romano pontífice (apdo. 1.1).

\subsubsection{Consejo Pontificio para el Diálogo Interreligioso (Constitución grupo de trabajo Santa Sede-Palestina)}

El 5 de diciembre se reunieron en Roma miembros del Consejo Pontificio para el Diálogo Interreligioso y de la Comisión Palestina para el Diálogo Interreligioso. El encuentro estuvo presidido por el card. Tauran y por Shaykh Mahmoud Al-Habbash, juez supremo del Estado de Palestina. Ambas partes acordaron la creación del Grupo de Trabajo Conjunto para el Diálogo entre la Santa Sede y Palestina.

\subsubsection{Consejo Pontificio para los Textos Legislativos (Respuestas particulares)}

- El 23 de febrero se respondió (Prot. N. 15760/2017) a la consulta sobre la corrección de la praxis de los tribunales eclesiásticos de una región italiana, tras la promulgación del Motu Proprio Mitis iudex, de comunicar con la citación a la parte demandada un mémoire junto con el libelo.

El Consejo Pontificio respondió indicando que el c. 1676, \$1 no prevé la notificación de este mémoire, por lo que se trata de una praxis que va más 
allá de lo pedido por la norma codicial. Se recuerda, además, que según el parágrafo 2 del mismo canon, corresponde al vicario judicial determinar mediante decreto si la causa debe tratarse con el procese ordinario o el más breve, sin necesidad de pedir a la parte citada nada al respecto. Si se establece que la causa se sustancie según el proceso más breve, se procederá según el c. 1685, sin tener en cuenta los cc. 1683-1684. El c. 1685 establece la obligación del vicario judicial de nombrar, en el mismo decreto con el que determina la fórmula de la duda, al instructor y al asesor y de citar a todos aquellos que deben participar en la sesión.

- El 2 de marzo, ante la pregunta de un abogado en relación a una duda sobre la libertad de las partes procesales de elegir abogados y procuradores propios (cfr. cc. 1481, $\$ 1$ CIC y 1139, $\$ 1$ CCEO) tras el rescripto de 7 de diciembre de 2015 del papa Francisco, este Consejo Pontificio respondió (cfr. Prot. N. 15822/2017) que es derecho de todo fiel la libre elección del propio abogado y procurador de confianza en los procesos canónicos y que el mencionado rescripto no justifica ninguna interpretación contraria a este derecho.

- Sobre la posibilidad de la sanación in radice de los matrimonios mixtos nulos se realizaron dos consultas. La primera fue contestada por carta de 24 de abril (Prot. N. 15814/2017). En ella se dice que la inclusión del matrimonio mixto en la cláusula general matrimonium irritum del canon 1163, $\$ 1$ consta claramente no sólo del texto de este canon, sino también en relación con el c. $1165, \$ 2$, donde expresamente se habla de los matrimonios mixtos.

La segunda respuesta ante la misma duda es de 22 de mayo (Prot. N. 15891/2017). Se recuerda, además, que el decreto de sanación debe hacer referencia a que persevera el consentimiento de ambas partes y que se cumplen las condiciones de los cc. 1125-1126 en relación con la dispensa concedida a los matrimonios mixtos.

- El 15 de noviembre se respondió a la consulta sobre si podían admitirse como padrinos de bautismo a dos no católicos y el problema de la anotación en el libro de bautismo de los padres cuando éstos son del mismo sexo o personas transexuales. El Consejo Pontificio responde a la primera aludiendo a la indicación del c. 874, $\$ 2$ de que el no católico sólo puede ser padrino junto con otro padrino católico. Respecto a la consulta concreta, pueden ser admitidos dos padrinos no católicos siempre que haya un tercero católico.

En relación con la segunda consulta, se responde que el término «padres» del c. $877, \$ 1$ se refiere claramente a padre y madre, hombre y mujer, 
unidos por el sacramento del matrimonio. En estos casos, el párroco debe anotar el nombre de los padres naturales o adoptivos, o sólo el de la madre soltera, y también el del padre si su paternidad se prueba por documento público (cfr. c. $877, \$ 2$ ). La anotación de parejas del mismo sexo o de transexuales sería contraria a la enseñanza del Señor y de la Iglesia. Si alguno de ellos es el padre o madre natural del niño, debe ser anotado en el libro; el otro miembro de la pareja no puede ser anotado. Se especifica, además, que no pueden ser registrados dos madres o dos padres, o un padre transexual cuya verdadera naturaleza es femenina, o viceversa.

- El 13 de junio se respondía (Prot. N. 15944/2017) a una consulta sobre el Tribunal interdiocesano del c. 1673, $\$ 2$ tras la reforma del Motu Proprio Mitis iudex. La respuesta remite al c. 1423 y al requisito del común acuerdo de todos los obispos interesados y de la autorización por parte de la Signatura Apostólica. A continuación aluden a la praxis observada en la Signatura, de que examinan el caso cuando los obispos solicitantes no pertenecen a la misma archidiócesis, pero que basta sólo con la notificación de la erección cuando todos tienen el mismo metropolitano.

\subsection{Comisiones pontificias}

Ecclesia Dei (Autorización para la celebración del matrimonio de los fieles de la Fraternidad San Pío X)

El 27 de marzo el card. Müller, prefecto de la Congregación para la Doctrina de la Fe, publicó una carta cuyo contenido fue aprobado por el papa Francisco en audiencia concedida el día 24 de ese mismo mes.

La carta va dirigida a los obispos de las diversas conferencias episcopales, autorizándoles a conceder licencias para asistir el matrimonio de fieles del entorno de la Fraternidad Sacerdotal San Pío X.

Esta disposición se enmarca en la línea pastoral promovida por el papa Francisco de ofrecer signos de acercamiento para facilitar el regreso a la plena comunión de la Fraternidad San Pío X, como ya lo hiciera en 2016 al conceder a los sacerdotes de esta institución facultades para confesar válida y lícitamente a los fieles que acuden a sus iglesias (cfr. carta ap. Misericordia et misera n. 12$)^{3}$.

${ }^{3}$ Cfr. J. Sedano, Crónica de Derecho Canónico 2016, Ius Canonicum 113 (2017) 392. 
En esta ocasión, la medida busca tranquilizar la conciencia de los fieles en relación con los matrimonios celebrados por los sacerdotes lefebvrianos, «no obstante, que la situación canónica de la Fraternidad San Pío X continúa siendo, por ahora, objetivamente ilegítima». Siempre que sea posible el obispo del lugar delegará esa facultad en un sacerdote de la diócesis, o de otra circunscripción eclesiástica con las debidas licencias, para que reciba el consentimiento de los cónyuges, que en el Vetus ordo se realiza al inicio de la Misa. A continuación, el sacerdote de la Fraternidad celebrará la Santa Misa. Cuando no sea posible la presencia del sacerdote diocesano o con plenas licencias, el obispo podrá conceder directamente dicha facultad al sacerdote de la Fraternidad que celebra la Misa.

\subsection{Tribunales}

\section{Tribunal de la Rota Romana (Interpretación del nuevo c. 1687)}

Sobre las nuevas competencias que atribuye la nueva redacción del c. 1687 al decano de la Rota Romana, vid. discurso del papa a los participantes en el curso organizado por la Rota Romana en Escritos y documentos (apdo. 1.1).

\subsection{Consejo de los nueve cardenales}

De las diversas reuniones tenidas a lo largo de 2017 por el Consejo de los nueve cardenales, varios han sido los asuntos estudiados que han sido dados a conocer a través de las notas de prensa. Entre ellos destacan los siguientes:

La posibilidad de que se realice una consulta más amplia entre el pueblo de Dios para la elaboración de la lista de candidatos al episcopado. También se ha tratado de la posibilidad de transferir a los obispos diocesanos o a las conferencias episcopales diversos poderes y facultades que en la actualidad son competencia de los dicasterios romanos. Otra cuestión que ha sido tratada es la conveniencia de contar en la curia romana con personal más profesional y una mayor presencia de mujeres y jóvenes ${ }^{4}$.

Por otra parte, el papa en su discurso a la curia romana por las fiestas de Navidad hizo referencia expresa a la relación de la curia con las Iglesias particulares, que debe configurarse como relación de servicio ${ }^{5}$.

\footnotetext{
${ }^{4}$ Cfr. Agencia de noticias Zenit, servicios de 14 de junio y 13 de septiembre de 2017.

${ }^{5}$ Cfr. Discurso de 21 de diciembre.
} 


\section{RELACiONES INTERNACIONALES DE LA SANTA SEDE \\ (Relaciones con Cbina; reunión Comisión bilateral permanente de trabajo}

Santa Sede-Estado de Israel; acuerdo marco con el Congo; relaciones diplomáticas plenas con Myanmar; grupo de trabajo Santa Sede-Palestina)

- Durante 2017, las relaciones entre el Vaticano y el gobierno chino continuaron caracterizadas por el habitual estado de tensión. El principal problema parece ser la búsqueda de un acuerdo sobre el sistema de nombramientos de los obispos. Pero no es el único. También preocupa en la Santa Sede la reconciliación de siete obispos ordenados ilícitamente, el reconocimiento por parte del gobierno de la treintena de obispos "clandestinos", la devolución de los bienes eclesiásticos, la posibilidad de establecer colegios católicos y las relaciones con la Asociación Patriótica Católica China.

En enero, la novena Asamblea de los representantes católicos eligió a los representantes de las dos organizaciones de la Iglesia católica tuteladas por el gobierno. El obispo ilegítimo de Kunming (Yuannan), Ma Yinglin, fue reelegido como presidente del Consejo de los Obispos; mientras que Fang Xingyao, obispo de Linyi (Shandong), reconocido por el Vaticano y por el gobierno, fue reelegido como presidente de la Asociación Patriótica.

Por otra parte, continuaron los arrestos de obispos por parte del gobierno. En 2017 fueron privados de libertad el obispo de Wenzhóu (Zhejiang), Pedro Shao Zhumin, Vicente Guo Xijin, obispo de Mindong (Fujian) y Tadeo Ma Daqin, obispo de Shanghai. Según diversos medios, parece ser que éste es un medio de presión utilizado por el gobierno para que todos los obispos se inscriban en la Asociación Patriótica, como requisito para llegar a un acuerdo con el Vaticano sobre los nombramientos episcopales ${ }^{6}$.

- El 18 de enero tuvo lugar en Jerusalén una nueva reunión de la sesión plenaria de la Comisión Bilateral Permanente de Trabajo entre la Santa Sede y el Estado de Israel para la continuación de las negociaciones en virtud del artículo 10, $\$ 2$ del Acuerdo Fundamental entre la Santa Sede y el Estado de Israel de 1993. El encuentro fue presidido por Tzachi Hanegbi, ministro de Cooperación Regional del Estado de Israel, y por mons. Antoine Camilleri, subsecretario para las Relaciones con los Estados.

\footnotetext{
${ }^{6}$ Más información en Agencia periodística Aceprensa, servicio de 1 de marzo de 2017; agencia de noticias Zenit, servicio de 11 de enero; Religión en Libertad, servicio de 16 de abril.
} 
El 13 de junio las mismas autoridades presidieron una nueva reunión de esta Comisión Bilateral, esta vez en el Vaticano.

- El 3 de febrero de 2017, en el Palacio del Pueblo de la República del Congo en Brazzaville, se firmó el acuerdo marco entre la Santa Sede y la República del Congo sobre las relaciones entre la Iglesia Católica y el Estado. El acto estuvo presidido por el presidente de la República, Denis Sassou-N'guesso, y fue firmado por el card. Parolin, secretario de Estado del Vaticano, y por Clément Mouamba, primer ministro del Congo.

La nota de prensa difundida por el Vaticano especifica que el acuerdo «consta de un preámbulo y 18 artículos, garantiza a la Iglesia la posibilidad de llevar a cabo su misión en el Congo. En particular, se reconoce la personalidad jurídica de la Iglesia y de sus instituciones. Las dos Partes, salvaguardando al mismo tiempo la independencia y autonomía propias, se comprometen a colaborar por el bien material moral, espiritual y de la persona humana y la promoción del bien común. El Acuerdo Marco entrará en vigor a partir del intercambio de instrumentos de ratificación».

- El 4 de mayo el romano pontífice recibió en audiencia a la ministra de Relaciones Exteriores de la República de la Unión del Myanmar (Birmania), Aung San Suu Kyi. Tras esta reunión se hizo público el establecimiento de relaciones diplomáticas plenas entre ambos Estados, esto es, a nivel de nunciatura apostólica por parte de la Santa Sede y de embajada por parte de Birmania.

Impulsado por el estrechamiento de las relaciones diplomáticas, el santo padre realizó un viaje apostólico a Myanmar del 26 de noviembre al 2 de diciembre.

- Sobre la creación del Grupo de Trabajo Conjunto para el Diálogo entre la Santa Sede y Palestina, vid. Consejo Pontificio para el Diálogo Interreligioso (apdo. 2.3.2).

- Al cierre del año 2017, la Santa Sede mantiene relaciones diplomáticas plenas con 183 países, a los que hay que añadir la Unión Europea y la Soberana Orden Militar de Malta. 


\section{CONFERENCIA EPISCOPAl EspaÑola}

(Estatutos de Santa María in Monserrato; unificación provincial de las Religiosas de María Inmaculada; unificación provincial de los Misioneros Paúles; nuevo Misal castellano; actualización normas de la BAC; aprobación y modificación de estatutos)

- El 15 de diciembre de 2016 el Comité ejecutivo de la Conferencia Episcopal aprobó el texto que modifica los estatutos del Convictorio eclesiástico de Santa María in Monserrato, que datan de 1950, y acordó su envío a la Congregación para el Clero para su preceptiva aprobación ${ }^{7}$.

- El 22 de enero las Religiosas de María Inmaculada, con presencia en 21 países y con 123 comunidades, fusionaron sus provincias de España en una sola, con sede en Madrid-Ríos ${ }^{8}$.

- El 25 de enero la Congregación de la Misión (Misioneros Paúles) fusionaron sus provincias de España (Barcelona, Madrid y Salamanca) en una única provincia9.

- El 4 de marzo, desde las primeras vísperas del domingo I de Cuaresma, se hizo obligatorio en el territorio de la Conferencia Episcopal Española el uso del nuevo Misal. Como ya se comentó en la Crónica del año pasado, se trata de una traducción que busca una mayor fidelidad al original latino, y cuyo cambio más significativo es la sustitución de la expresión «por todos los hombres» por la de «por muchos» en la fórmula de la consagración del vino.

- La CCXL reunión de la Comisión permanente de la Conferencia Episcopal (21-22 de febrero) aprobó la actualización de las normas de funcionamiento de la Biblioteca de Autores Cristianos (BAC) ${ }^{10}$.

- La CIX Asamblea plenaria de la Conferencia Episcopal (17-21 de abril) aprobó la modificación de estatutos de la Federación del Escultismo Valenciano - Movimiento Scout Católico. A petición de la propia institución, procedió a la disolución de la Asociación de Sacerdotes de la OCSHA, asociación pública de fieles de ámbito nacional y clerical ${ }^{11}$.

\footnotetext{
7 Cfr. BOCEE 99 (2017) 3-11.

Cfr. revista Ecclesia 3873 (2017) 306.

9 Cfr. ibid., 3877 (2017) 472.

${ }^{10}$ Cfr. BOCEE 99 (2017) 33-34.

${ }^{11}$ Cfr. ibid., 30.
} 
- Durante la CX Asamblea plenaria de la Conferencia Episcopal (20-24 de noviembre) se aprobó la modificación de los estatutos de la Fraternidad Cristiana de Personas con Discapacidad (FRATER) y de los Ciegos Españoles Católicos (CECO). También se aprobaron los estatutos de las siguientes instituciones: fundación pía autónoma privada Fundación Educativa fesuitinas, Fundación Educativa Franciscanas Ana Mogas.

Durante la misma Asamblea, se aprobó remitir los nuevos estatutos del Pontificio Colegio Español de San Fosé de Roma a la Congregación para el Clero en espera de su aprobación definitiva. 



\section{BIBLIOGRAFÍA}

RECENSIONES 
